\title{
Níveis de Substituição do Leite em Pó Desnatado pelo Isolado Protéico de Soja na Dieta de Leitões Desmamados ${ }^{1}$
}

\author{
Otto Mack Junqueira², Liliam Zambrana Toledo Silz ${ }^{3}$, Lúcio Francelino Araújo4, Eurípedes \\ Laurindo Lopes $^{5}$, Karina Ferreira Duarte ${ }^{6}$
}

\begin{abstract}
RESUMO - Objetivou-se verificar o efeito da substituição do leite desnatado em pó pelo isolado protéico de soja em rações para leitões desmamados aos 21 dias de idade sobre o desempenho, a morfometria intestinal e relação peso de pâncreas/peso de carcaça. Foram utilizados 80 leitões desmamados, no período de 21 a 35 dias de idade, distribuídos em delineamento de blocos ao acaso com cinco tratamentos, quatro repetições e quatro animais por unidade experimental (dois machos e duas fêmeas), totalizando 16 leitões por tratamento. Os tratamentos consistiram na substituição protéica (0, 25, 50, 75 e 100\%) do leite desnatado em pó pelo isolado protéico de soja. Todas as dietas apresentaram mesmo conteúdo protéico (20,00\%), energético (3420 kcal ED/kg de dieta) e de lactose (8,16\%). Foram analisados parâmetros de desempenho (ganho de peso, consumo e conversão alimentar) e relação entre peso de pâncreas/peso de carcaça. Realizou-se análise morfométrica do intestino delgado, abatendo-se seis animais/tratamento ao término do período experimental. Observou-se efeito quadrático dos tratamentos para ganho de peso e conversão alimentar e efeito linear negativo para consumo de ração. Não houve alterações morfométricas para altura de vilosidade, profundidade de criptas e para a relação entre peso de pâncreas/peso de carcaça. Concluiu-se que o isolado protéico de soja pode substituir a proteína do leite em pó desnatado em 34,25\% para máximo ganho de peso e 51,00\% para melhor conversão alimentar. A substituição total da proteína láctea pela proteína da soja não afetou a integridade do vilo e a relação entre peso de pâncreas/peso de carcaça.
\end{abstract}

Palavras-chave: desempenho, isolado protéico de soja, leite desnatado em pó, leitões, morfologia intestinal

\section{Substitution Levels of Dry Skim Milk for Isolated Soybean Protein in Diets of Weaned Pigs}

\begin{abstract}
One experiment was conducted to study the effect of the substitution of dry skim milk for isolated soybean protein in diets of piglets from 21 to 35 days of age. It was used 80 piglets in a experimental design involved 5 treatments, 4 blocks of 4 animals each in a total of 16 piglets per treatment. The treatments constituted the levels of substitution ( $0 \%, 25 \%, 50 \%, 75 \%$ and $100 \%)$ of the protein furnished by dry skim milk for isolated soybean protein. All the diets contained $20.00 \%$ crude protein, 3420kcal D.E./kg and 8.16\% lactose and 1.20 lysine. It was observed a quadratic effect for weight gain and feed conversion and a linear effect for feed intake. There was not statistical effect of villus height, crypt depth and pancreas weight/carcass weight ration. It was concluded that isolated soybean protein may be used in the diet of piglets until the level of $34.25 \%$ for weight gain, and $51.00 \%$ for feed conversion in substitution of the protein furnished by dry skim milk. The total substitution of milk protein by soybean protein did not affect the villus integrity and the ratio pancreas weight/carcass weight.
\end{abstract}

Key Words: dry skim milk, intestinal morphology, isolated soybean protein, performance, piglets

\section{Introdução}

O desenvolvimento tecnológico da suinocultura demanda maior produção por porca/ano. Para alcançar as metas estimadas, a diminuição da idade de desmame tem sido uma prática constante. Há a necessidade de se utilizar ingredientes mais digestíveis nas rações, para evitar transtornos gastrointestinais na fase de adaptação dos leitões às novas dietas após o desmame.
Pesquisas recentes têm demonstrado que o leite desnatado em pó pode ser substituído por outras fontes protéicas, sem afetar o desempenho. Entre as fontes alternativas, pode-se mencionar o isolado e o concentrado protéico de soja. Estes produtos causam redução da reação de hipersensibilidade transitória causada pelo farelo de soja, o que se manifesta pelo aumento no tamanho das vilosidades intestinais, pela melhoria na digestibilidade e pelo maior ganho de peso, quando comparados com farelo de soja (Robles, 1993).

\footnotetext{
1 Projeto financiado pela FAPESP - no 97/7449-9

2 Docente Departamento de Zootecnia FCAV - UNESP/Jaboticabal - SP. E.mail: ottomack@fcav.unesp.br

3 Médica Veterinária, Doutora em Zootecnia pela FCAV/UNESP- Jaboticabal-SP.

4 Docente Departamento de Zootecnia FZEA - USP/Pirassununga - SP. E.mail: Ifaraujo@usp.br

5 Docente Departamento de Produção Animal EV - UFG/Goiânia - GO. E.mail: ellopes@vet.ufg.br

6 Aluna do curso de Mestrado em Zootecnia FCAV - UNESP/Jaboticabal - SP.
} 
A substituição da proteína do leite desnatado em pó pela proteína do milho e do farelo de soja em dietas úmidas e secas, isonitrogenadas $(21,8 \% \mathrm{~PB})$ e isocalóricas (4,04 Mcal ED/kg dieta) para leitões dos 2 aos 23 dias pós-desmame piorou o ganho de peso médio e a conversão alimentar, à medida que se diminuiu a proteína láctea da dieta (Sherry et al., 1978). Resultados semelhantes foram observados por Li et al. (1990) e Li et al. (1991a), em leitões desmamados aos 14 e 21 dias de idade, alimentados com dietas contendo soro de leite em pó ou leite em pó desnatado, apresentaram ganho de peso superior aos animais alimentados com dietas à base de milho e farelo de soja.

Pond et al. (1971) em estudos comparativos com concentrado protéico de peixe (FPC), caseína, ou isolado protéico de soja (ISP), em dietas isonitrogenadas e líquidas (200g MS/L) para leitões dos 2 aos 21 dias pós-desmame, observaram que o ISP foi inferior ao FPC e à caseína na promoção de crescimento e concentração sérica total. Resultado semelhante foi obtido por Mateo \& Veum (1980), com leitões até 15 dias pós-desmame, recebendo dietas líquidas (20\% MS), quando compararam a utilização de caseína e ISP.

Quando metade do leite desnatado em pó em dietas líquidas (20\% de matéria seca) foi substituída pelo isolado protéico de soja, o desempenho, medido como ganho de peso e conversão alimentar, dos leitões não foi afetado. Porém, observou-se mortalidade extrema associada à substituição total do leite pelo ISP, o que indicou severa dificuldade digestiva dos leitões ou efeito tóxico (Newport, 1980). A substituição total da proteína láctea pelo ISP em dietas isonitrogenadas, resultou em ganho de peso de $60 \%$ em relação às dietas contendo proteína láctea (Wilson \& Leibholz, 1981a). Porém, em trabalho realizado por vários autores (Newport, 1980; Newport \& Keal, 1982) foi observado crescimento muito pequeno quando o ISP substituiu em $70 \%$ e $74 \%$ a proteína láctea, havendo grande mortalidade associada a diarréias. Aproximadamente um terço da proteína em uma dieta com leite como única fonte protéica, pode ser substituído pelo isolado protéico de soja sem afetar o desempenho (Newport \& Keal, 1982).

Grant et al. (1990) estudaram o efeito da substituição de $20 \%$ da proteína da dieta totalmente láctea pelo isolado protéico de soja para leitões alimentados com dietas líquidas (15\%MS) e observaram que o ganho de peso diário não diferiu entre as dietas, resultados comprovados por Sohn et al. (1994a), em estudo com leitões desmamados aos 21 dias e criados até os 28 dias de idade, alimentados com leite desnatado em pó (40\% da dieta) ou isolado protéico de soja solúvel einsolúvel a 20,29\% da dieta ou concentrado protéico de soja (25,09\%). Neste estudo, os autores relataram ainda que as três fontes protéicas supracitadas foram superiores em relação ao ganho de peso e à eficiência alimentar quando comparadas com o farelo de soja (24,12\% da dieta), porém esta diferença no desempenho dos animais desapareceu após três semanas subseqüentes ao teste, quando todos os animais receberam a mesma ração comercial.

Dunsford et al. (1989) observaram diminuição no tamanho do vilo intestinal e aumento da lâmina própria, em leitões desmamados aos 21 dias e alimentados com dietas à base de milho e farelo de soja e caseína, sugerindo que o fornecimento de altas concentrações de farelo de soja ( $44 \%$ da dieta), após o desmame, tem efeito deletério no intestino delgado, minimizado quando o farelo de soja é adicionado às dietas à base de milho.

Leitões desmamados aos 21 dias de idade e alimentados com 35\% de leite desnatado em pó na dieta apresentaram maior comprimento de vilo que os alimentados com 38\% de farelo de soja, e também maiores vilos que os alimentados com produtos de soja (24\% de concentrado protéico de soja, $24 \%$ de concentrado protéico de soja extrusada e $21 \%$ isolado protéico de soja na dieta). Estes, no entanto, tiveram vilos mais longos, maiores áreas de vilo e maior comprimento de perímetro de vilo que os alimentados com farelo de soja, indicando que o processamento do farelo de soja deixa-o mais disponível para a alimentação de leitões jovens (Li et al., 1991a).

Owsley et al. (1986) e Chen et al. (1992) não observaram efeito quando substituíram 0 e $20 \%$ de soro de leite em pó em dieta à base de milho e farelo de soja sobre o peso de pâncreas, em leitões desmamados aos 28 dias de idade. Porém, leitões desmamados aos 21 e 28 dias de idade, alimentados com dietas à base de milho e farelo de soja apresentaram peso de pâncreas menor que os alimentados com dietas contendo milho, farelo de soja e soro de leite em pó (Lindemann et al., 1986; Cera et al., 1990).

Objetivou-se avaliar os efeitos da inclusão do isolado protéico de soja em substituição à proteína láctea sobre o desempenho, a morfometria intestinal e a relação peso de pâncreas/peso de carcaça de leitões dos 21 aos 35 dias de idade. 


\section{Material e Métodos}

Um experimento foi conduzido na Faculdade de Medicina Veterinária e Zootecnia da Universidade de São Paulo, Campus de Pirassununga com leitões provenientes de granja de linhagem comercial. Os leitões foram alojados em gaiolas coletivas suspensas, com capacidade para quatro animais/gaiola, em galpão de alvenaria, coberto com telhas de cerâmica, com pé direito de 3,00 metros e laterais protegidas por tela e cortinas plásticas.

Em um período experimental de 15 dias, dos 21 aos 35 dias de idade, foram utilizados 80 leitões (40 machose 40 fêmeas)com peso inicial de $5,78 \pm 0,15 \mathrm{~kg}$, distribuídos em delineamento experimental de blocos casualizados, com cinco tratamentos, quatro repetições e quatro leitões por unidade experimental (dois machos e duas fêmeas), totalizando 16 leitões por tratamento. Aos 28 dias de idade, os animais e as rações também foram pesados para avaliação do desempenho dos animais na primeira semana após o desmame.

Os tratamentos consistiram dos níveis de substituição protéica do leite desnatado em pó pelo isolado protéico de soja (0\%, 25\%, 50\%, 75\% e 100\%), sendo que os níveis de leite desnatado em pó foram reduzidos com subseqüentes aumentos do isolado protéico de soja e lactose, de maneira a manter todas as dietas com um mesmo conteúdo protéico (20,00\% de PB), energético (3.420 kcal ED/kg de dieta) e de lactose (8,16\%), conforme Tabelas 1 e 2 .

As exigências nutricionais foram baseadas nas sugestões de Easter et al (1994), sendo os alimentos e a água fornecidos ad libitum.

Após o término do período experimental, seis animais de cada tratamento foram abatidos por secção da veia jugular, para coleta de pâncreas e fragmentos do intestino delgado, assim como para a pesagem das carcaças.

Amostras da porção proximal do duodeno de, aproximadamente, $1 \mathrm{~cm}$ de comprimento foram coletadas de cada animal, abertas pela borda mesentérica, lavadas, estendidas pela túnica serosa e fixadas em solução de Bouin, em frascos de vidros identificados com o número de cada animal, para posterior processamento.

Depois de 24 horas na solução fixadora de Bouin, as amostras foram lavadas em álcool etílico a $70 \%$, e posteriormente desidratadas em série crescente de alcoóis. Após desidratação, foram recortadas, diafanizadas em benzol e incluídas em parafina, de modo a se obter cortes longitudinais da mucosa intestinal.

Em cada lâmina histológica, foram colocados seis cortes semi-seriados com $5 \mathrm{~mm}$ de espessura, sendo

Tabela 1 - Composição centesimal das dietas experimentais

Table 1 - Centesimal composition of the experimental diets

\begin{tabular}{|c|c|c|c|c|c|}
\hline $\begin{array}{l}\text { Ingredientes (\%) } \\
\text { Ingredient }\end{array}$ & $\begin{array}{c}\text { Dieta A } \\
\text { Diet A }\end{array}$ & $\begin{array}{c}\text { Dieta B } \\
\text { Diet B }\end{array}$ & $\begin{array}{c}\text { Dieta C } \\
\text { Diet } C\end{array}$ & $\begin{array}{l}\text { Dieta D } \\
\text { Diet } D\end{array}$ & $\begin{array}{l}\text { Dieta E } \\
\text { Diet E }\end{array}$ \\
\hline Milho (Corn) & 61,24 & 61,09 & 60,68 & 60,31 & 59,91 \\
\hline Farelo de soja (46\%) (Soybean meal46\%) & 16,35 & 16,42 & 16,56 & 16,67 & 16,79 \\
\hline Leite desnatado pó (Dry skim milk) & 16,00 & 12,00 & 8,00 & 4,00 & - \\
\hline Isolado protéico de soja ${ }^{1}$ (Isolated soybean meal) & - & 1,47 & 2,93 & 4,40 & 5,87 \\
\hline Lactose (Lactose) & - & 2,06 & 4,12 & 6,18 & 8,24 \\
\hline Óleo (Oil) & - & 0,41 & 0,92 & 1,42 & 1,93 \\
\hline Protenose (Corn gluten meal) & 3,00 & 3,00 & 3,00 & 3,00 & 3,00 \\
\hline Calcário calcítico(Limestone) & 0,84 & 0,83 & 0,87 & 0,91 & 0,95 \\
\hline Fosfato bicálcico (Dicalcium phosphate) & 1,49 & 1,62 & 1,75 & 1,88 & 2,01 \\
\hline L-lisina (L-lysine) & 0,15 & 0,17 & 0,19 & 0,21 & 0,23 \\
\hline Mistura vitamínica ${ }^{2}$ (Vitamin premix) & 0,10 & 0,10 & 0,10 & 0,10 & 0,10 \\
\hline Mistura mineral ${ }^{3}$ (Mineral premix) & 0,10 & 0,10 & 0,10 & 0,10 & 0,10 \\
\hline Óxido de zinco (Zinc oxide) & 0,35 & 0,35 & 0,35 & 0,35 & 0,35 \\
\hline Sal (Salt) & 0,38 & 0,38 & 0,43 & 0,47 & 0,52 \\
\hline Total (Total) & 100,00 & 100,00 & 100,00 & 100,00 & 100,00 \\
\hline
\end{tabular}

${ }^{1}$ Isolado protéico de soja contendo (Isolated soybean meal content): $90 \%$ de proteína bruta (Crude protein); 1,0\% gordura (Fat); 5,5\% lisina (Lysine); 1,2\% metionina (Methionine); 1,1\% triptofano(Trypthophan); 2,3\% de aminoácidos sulfurados totais (Total sulfur aminoacids).

${ }^{2}$ Níveis de garantia por kg de ração (Added/kg of ration): Vit. A : $9.000 \mathrm{UI}$; Vit. D3: $1.800 \mathrm{UI}$; Vit. E: $18,00 \mathrm{mg}$; Vit.K3: 1,60 mg; Vit. B1: 1,40 mg; Vit.B2: 4,00 mg; Vit. B6: 1,40mg; Vit. B12: 18,00 mcg; Niacina (Niacin): 30,00 mg; Ácido pantotênico (Panthotenic acid): 16,00 mg; Ácido fólico (Folic acid): 0,40 mg; Biotina(Biotin): 0,10 mg; Antioxidante (Antioxidant): 100,00 mg;

${ }^{3}$ Níveis de garantia por $\mathrm{kg}$ de ração (Added/kg of ration): 80,00 mg Fe; 12,00 mg Cu; 70,00 mg Mn; 100,00 mg Zn; 1,00 mg l; 0,12 mg Se.

R. Bras. Zootec., v.33, n.6, p.2283-2291, 2004 (Supl. 3) 
Tabela 2 - Níveis nutricionais das dietas experimentais

Table 2 - Nutrition levels of the experimental diets

\begin{tabular}{|c|c|c|c|c|c|}
\hline $\begin{array}{l}\text { Níveis nutricionais } \\
\text { Nutrition levels }\end{array}$ & $\begin{array}{c}\text { Dieta A } \\
\text { Diet A }\end{array}$ & $\begin{array}{l}\text { Dieta B } \\
\text { Diet B }\end{array}$ & $\begin{array}{l}\text { Dieta C } \\
\text { Diet } C\end{array}$ & $\begin{array}{l}\text { Dieta D } \\
\text { Diet } D\end{array}$ & $\begin{array}{l}\text { Dieta E } \\
\text { Diet } E\end{array}$ \\
\hline $\mathrm{ED}(\mathrm{kcal} / \mathrm{kg})(\mathrm{DE}, \mathrm{kcal} / \mathrm{kg})$ & 3420 & 3420 & 3420 & 3420 & 3420 \\
\hline Proteína bruta (\%) (Crude protein, \%) & 20,00 & 20,00 & 20,00 & 20,00 & 20,00 \\
\hline Fibra bruta (\%) (Crude fiber, \%) & 2,20 & 2,20 & 2,20 & 2,20 & 2,20 \\
\hline Lactose (\%) (Lactose, \%) & 8,16 & 8,16 & 8,16 & 8,16 & 8,16 \\
\hline Cálcio(\%) (Calcium, \%) & 0,97 & 0,95 & 0,95 & 0,95 & 0,95 \\
\hline Fósforo disponível (\%) (Available phosphorus, \%) & 0,52 & 0,51 & 0,50 & 0,50 & 0,49 \\
\hline Fósforo total (\%) (Total phosphorus, \%) & 0,70 & 0,70 & 0,70 & 0,70 & 0,70 \\
\hline Sódio (\%) (Sodium, \%) & 0,24 & 0,22 & 0,22 & 0,22 & 0,22 \\
\hline Lisina total (\%) (Total lysine, \%) & 1,20 & 1,20 & 1,20 & 1,20 & 1,20 \\
\hline Metionina total (\%) (Total methionine, \%) & 0,40 & 0,38 & 0,37 & 0,35 & 0,33 \\
\hline Met+cist total $(\%)($ Total met + cys, \%) & 0,72 & 0,70 & 0,69 & 0,67 & 0,65 \\
\hline Triptofano total (\%) (Total tryptophan, \%) & 0,24 & 0,24 & 0,24 & 0,23 & 0,23 \\
\hline Treonina total (\%) (Total threonine, \%) & 0,81 & 0,75 & 0,70 & 0,64 & 0,59 \\
\hline
\end{tabular}

que entre um corte e o subseqüente foram desprezados seis cortes. Os cortes foram corados segundo as técnicas da hematoxilina de Harris-eosina.

Com as lâminas prontas, foram efetuadas 30 medidas de altura de vilosidades (micra) e 30 de profundidade de cripta (micra) para o segmento do duodeno coletado.

As medidas de HVILOS foram tomadas a partir da região basal, que coincide com a porção superior das criptas, percorrendo-a longitudinalmente até seu ápice, e as criptas, da sua base até a região de transição cripta-vilo. A análise morfométrica do intestino delgado foi realizada em um sistema analisador de imagens da KONTRON ELEKTRONIK (Vídeo Plan) por meio de microscopia de luz, com aumento de 230 vezes.

A análise estatística dos dados obtidos foi realizada por intermédio do programa SAS (SAS, 1988). Foram feitas análises de regressão linear e quadrática para os parâmetros estudados.

\section{Resultados e Discussão}

Os valores registrados para consumo médio (Tabela 3) apresentaram efeito linear $(\mathrm{P}<0,05)$, segundo a equação $y=4,3202-0,0091 x\left(R^{2}=0,6716\right)$ durante o período de 21 a 35 dias de idade. Na Figura 1, observa-se que o efeito foi negativo, pois, à medida que se aumenta o nível de substituição da proteína láctea pela proteína da soja, diminui-se o consumo. Entretanto, efeito linear negativo não foi observado durante o período de 21 a 28 dias de idade.

Segundo Etheridge et al. (1984), o maior consumo de dietas pouco digestíveis seria a causa da diarréia pós-desmame. Neste experimento, não foram observadas diarréias nos tratamentos, apesar de o consumo ter declinado com a inclusão do isolado protéico de soja na dieta. A inclusão acima de $3 \%$ do isolado protéico de soja na dieta reduziu drasticamente o consumo de ração no período de 21 a 35 dias de idade dos leitões. Ausência de distúrbios gastrointestinais durante o período experimental poderia estar relacionada à melhoria da digestibilidade da proteína da soja em produtos de soja processado, o que já foi comprovado por Decuypere et al. (1981).

Os resultados deste experimento não estão de acordo com os reportados por Walker et al. (1986), que não observaram diferenças nos consumos de leitões criados com diferentes fontes de soja e proteína láctea.

Os resultados para ganho de peso obtidos durante o período experimental estão apresentados na Tabela 4. Por intermédio da análise de regressão, observou-se efeito quadrático $(\mathrm{P}<0,10)$ segundo a equação $\mathrm{y}=2,4126+0,0137 \mathrm{x}-0,0002 \mathrm{x}^{2}\left(\mathrm{R}^{2}=0,9283\right)$ durante o período de 21 a 35 dias de idade. Com a substituição de 34,25\% da proteína láctea pela proteína da soja, obteve-se ganho de peso máximo estimado de 2,65 kg (Figura 2). Não se observou efeito decorrente da substituição da proteína láctea pela proteína da soja durante o período de 21 a 28 dias de idade.

Os menores resultados de ganho de peso nos níveis de substituição de $75 \%$ e $100 \%$ podem ter ocorrido em função dos baixos níveis de outros aminoácidos essenciais, particularmente a treonina, cuja relação à lisina, foi, respectivamente, de 53,3\%

R. Bras. Zootec., v.33, n.6, p.2283-2291, 2004 (Supl. 3) 
Tabela 3 - Níveis de substituição do leite em pó desnatado pelo isolado protéico de soja sobre o consumo de ração de leitões desmamados

Table 3 - Substitution levels of dry skim milk for isolated soybean protein on feed intake from piglets

\begin{tabular}{|c|c|c|c|c|c|c|}
\hline \multirow[t]{2}{*}{$\begin{array}{l}\text { Variáveis } \\
\text { Variables }\end{array}$} & \multicolumn{5}{|c|}{$\begin{array}{c}\text { Níveis de substituição (\%) } \\
\text { Substituition levels (\%) }\end{array}$} & \multirow[t]{2}{*}{ CV (\%) } \\
\hline & 0 & 25 & 50 & 75 & 100 & \\
\hline $\begin{array}{l}\text { Consumo }(\mathrm{kg}) 21-28 \text { dias* } \\
\text { Feed intake }(\mathrm{kg}) 21-28 \text { days }\end{array}$ & 1,343 & 1,368 & 1,398 & 1,035 & 0,988 & 22,256 \\
\hline $\begin{array}{l}\text { Consumo (kg) 21-35 dias ** } \\
\text { Feed intake (kg) 21-35 days }\end{array}$ & 4,165 & 4,306 & 4,321 & 3,283 & 3,253 & 17,070 \\
\hline
\end{tabular}

* n.s. não-significativo pelo teste $F$.

** Efeito linear $(P<0,05)$.

* n.s. not significant by $F$ test.

** Linear effect $(P<.05)$.

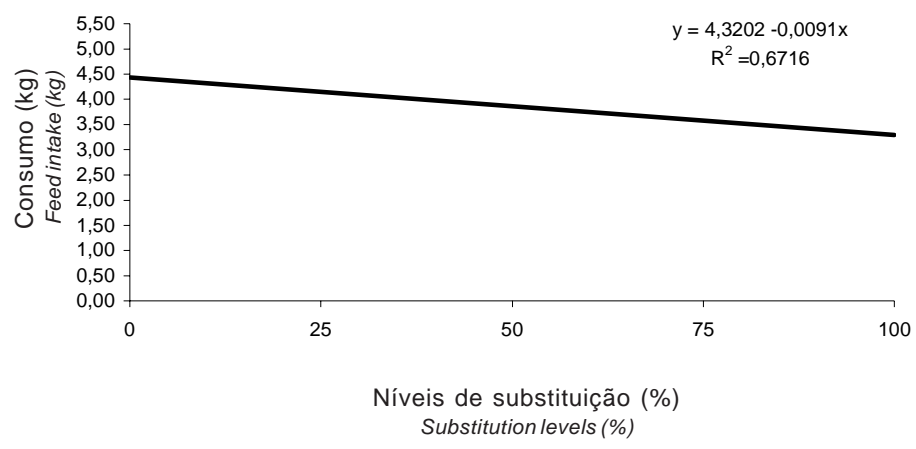

Figura 1 - Níveis de substituição do leite em pó desnatado pelo isolado protéico de soja sobre o consumo de ração de leitões desmamados de 21 a 35 dias de idade.

Figure 1 - Substitution levels of dry skim milk for isolated soybean protein on feed intake from piglets from 21 to 35 days of age.

e 49,2\%, valores abaixo dos referendados pela maioria das tabelas de exigências nutricionais, como Rostagno et al. (2000), que preconizam o valor de treonina total como $67 \%$ da lisina total na fase inicial de criação.

As anormalidades digestivas observadas em leitões desmamados e criados com farelo de soja (Newby, 1985; Stokes et al., 1987) não foram demonstradas neste experimento, fortalecendo a hipótese de Li et al. (1991a) e Sohn et al. (1994b) de que o processamento do farelo de soja poderia diminuir os fatores alergênicos presentes neste ingrediente, o que poderia resultar em desempenho inferior de leitões criados com a proteína da soja. Os resultados apresentados neste experimento estão em acordo com o trabalho de Robles (1993), que, ao utilizar o

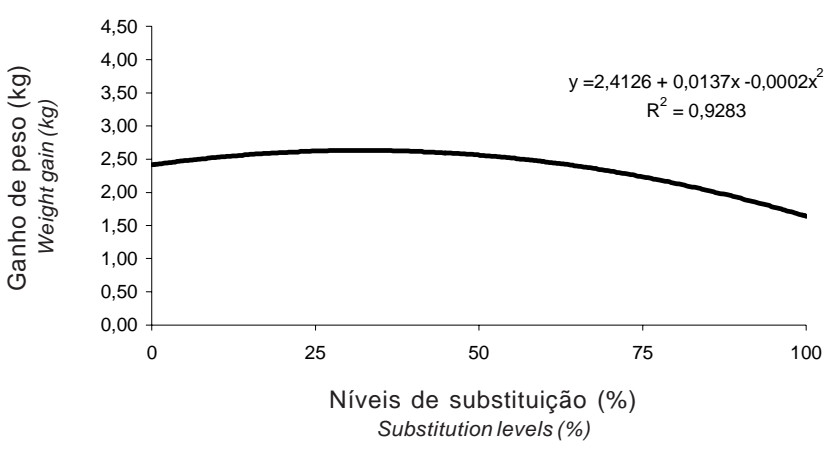

Figura 2 - Níveis de substituição do leite em pó desnatado pelo isolado protéico de soja sobre o ganho de peso de leitões desmamados.

Figure 2 - Substitution levels of dry skim milk for isolated soybean protein on weight gain from piglets. isolado protéico de soja, observou diminuição na hipersensibilidade passageira causada pelo farelo de soja, manifestando-se em melhora do ganho de peso.

Os efeitos deletérios da substituição da proteína láctea pelo farelo de soja sobre o ganho de peso observados durante a fase inicial de desenvolvimento por Li et al. (1990) e Li et al. (1991a) não foram verificados neste trabalho ao se utilizar o isolado protéico de soja em 34,25\% de substituição. Os resultados apresentados neste experimento não estão em acordo com Grant et al. (1990) e Sohn et al. (1994a), que não observaram diferença no ganho de peso entre leitões alimentados com proteína láctea e leitões que receberam isolado protéico de soja. No entanto, Newport \& Keal (1982)e Walker et al.(1986) observaram que a substituição de $70 \%$ a $74 \%$ da 
proteína láctea pelo isolado protéico de soja resultou em piora no ganho de peso, o que em parte está de acordo com os dados apresentados, uma vez que obteve-se melhora do ganho de peso com até 34,25\% de substituição da proteína láctea pela proteína da soja, com posterior declínio.

O alto coeficiente de variação para ganho de peso no período de 21 a 28 dias de idade pode estar relacionado à adaptação dos animais ao experimento, quando os animais sofreram mudanças bruscas não só de alimentação, mas também sociais e de ambiente. Este coeficiente de variação diminuiu bruscamente quando considerado o período total (21 aos 35 dias de idade). Segundo Wilson \& Leibholz (1981ab), a digestibilidade aparente do nitrogênio no íleo e de todo o trato gastrointestinal em leitões alimentados com isolado protéico de soja aumenta dos 14 aos 35 dias de idade, o que também pode ter contribuído para a diminuição do coeficiente de variação neste período.
Os valores obtidos para conversão alimentar (Tabela 5), no período de 21 a 35 dias de idade, apresentaram efeito quadrático $(\mathrm{P}<0,10)$ segundo a equação $y=1,7981-0,0102 x+0,0001 x^{2}\left(R^{2}=0,7827\right)$, sendo que nonível de $51,00 \%$ de substituição da proteína láctea pela proteína da soja, obteve-se o melhor índice de conversão alimentar, na ordem de 1,538 (Figura 3). No período de 21 a 28 dias, não se observou efeito da substituição do leite desnatado em pó pelo isolado protéico de soja para a conversão alimentar.

A substituição do leite desnatado em pó pela proteína do farelo de soja acarreta piora da conversão alimentar (Sherry et al., 1978; Walker et al., 1986), porém os dados deste experimento demonstraram que obtêm-se melhora da conversão alimentar até $51 \%$ de substituição da proteína láctea pela proteína da soja. No entanto, Mateo \& Veum (1980) e Newport (1980) não observaram alteração da conversão alimentar com a substituição da fonte protéica.

Tabela 4 - Níveis de substituição do leite em pó desnatado pelo isolado protéico de soja sobre o ganho de peso de leitões desmamados

Table 4 - Substitution levels of dry skim milk for isolated soybean protein on weight gain of piglets

\begin{tabular}{|c|c|c|c|c|c|c|}
\hline \multirow[t]{2}{*}{$\begin{array}{l}\text { Variáveis } \\
\text { Variables }\end{array}$} & \multicolumn{5}{|c|}{$\begin{array}{l}\text { Níveis de substituição (\%) } \\
\text { Substituition levels (\%) }\end{array}$} & \multirow[t]{2}{*}{ CV $(\%)$} \\
\hline & 0 & 25 & 50 & 75 & 100 & \\
\hline $\begin{array}{l}\text { Ganho em peso (kg) } 21-28 \text { dias* } \\
\text { Weight gain (kg) } 21-28 \text { days }\end{array}$ & 0,725 & 0,905 & 0,853 & 0,565 & 0,400 & 50,514 \\
\hline $\begin{array}{l}\text { Ganho em peso }(\mathrm{kg}) 21-35 \text { dias** } \\
\text { Weight gain }(\mathrm{kg}) 21-35 \text { days }\end{array}$ & 2,365 & 2,700 & 2,636 & 2,063 & 1,715 & 24,139 \\
\hline
\end{tabular}

Tabela 5 - Níveis de substituição do leite em pó desnatado pelo isolado protéico de soja sobre a conversão alimentar (CA) de leitões desmamados

Table 5 - Substitution levels of dry skim milk for isolated soybean protein on feed conversion (FC) of piglets

\begin{tabular}{|c|c|c|c|c|c|c|}
\hline \multirow[t]{2}{*}{$\begin{array}{l}\text { Variáveis } \\
\text { Variables }\end{array}$} & \multicolumn{5}{|c|}{$\begin{array}{l}\text { Níveis de substituição (\%) } \\
\text { Substituition levels (\%) }\end{array}$} & \multirow[t]{2}{*}{ CV (\%) } \\
\hline & 0 & 25 & 50 & 75 & 100 & \\
\hline $\begin{array}{l}\text { CA }(\mathrm{kg} / \mathrm{kg}) 21-28 \text { dias* } \\
\text { FC }(\mathrm{kg} / \mathrm{kg}) 21-28 \text { days }\end{array}$ & 1,852 & 1,512 & 1,639 & 1,832 & 2,470 & 32,515 \\
\hline $\begin{array}{l}\text { CA }(\mathrm{kg} / \mathrm{kg}) 21-35 \text { dias** } \\
\text { FC }(\mathrm{kg} / \mathrm{kg}) 21-35 \text { days }\end{array}$ & 1,761 & 1,595 & 1,639 & 1,591 & 1,897 & 17,034 \\
\hline
\end{tabular}

* n.s. não-significativo pelo teste $F$.

** Efeito linear $(P<0,05)$.

* n.s. not significant by $F$ test.

** Linear effect $(P<.05)$.

R. Bras. Zootec., v.33, n.6, p.2283-2291, 2004 (Supl. 3) 
A substituição da proteína láctea pela proteína da soja não alterou a altura do vilo e a profundidade de cripta $(\mathrm{P}>0.05)$ em nenhum dos períodos estudados (Tabela 6). As respostas morfológicas do intestino delgado ao desmame, como a mudança de seu formato, com conseqüente encurtamento do vilo (Cera et al., 1988; Nabuurs, 1995), não foram observadas aos 14 dias pós-desmame entre os tratamentos. Estas respostas parecem ser muito visíveis quando leitões são alimentados com o farelo de soja (Stokes et al., 1987; Dunsford et al., 1989, Ratcliffe et al., 1989; Li et al., 1991ab), porém, quando recebem proteína de soja processada, estas alterações morfológicas podem ser minimizadas (Li et al., 1991a).

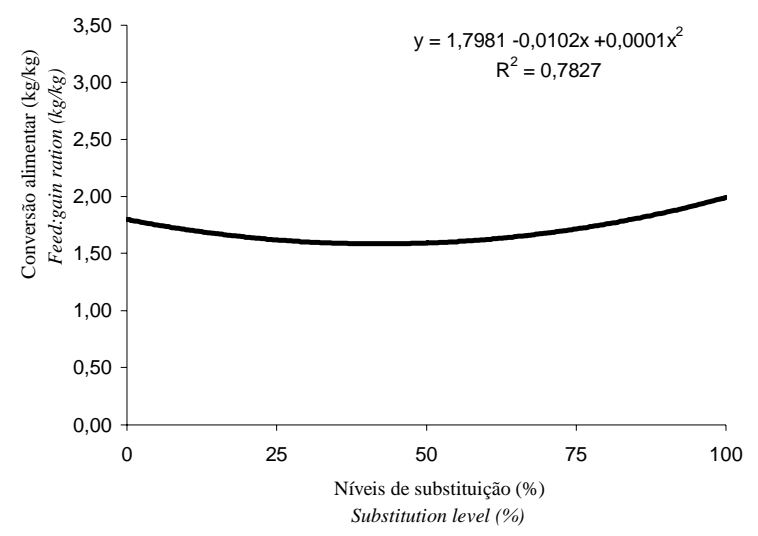

Figura 3 - Níveis de substituição do leite em pó desnatado pelo isolado protéico de soja sobre a conversão alimentar de ração de leitões desmamados.

Figure 3 - Substitution levels of dry skim milk for isolated soybean protein on feed conversion from piglets.
O fato de dietas contendo isolado protéico de soja não terem modificado o tamanho do vilo em relação à dieta contendo somente proteína láctea poderia estar relacionado à digestibilidade da proteína da soja processada, que é semelhante à proteína do leite (Sohn et al., 1994b), pois dietas altamente digestíveis e absorvíveis podem minimizar as mudanças abruptas durante a fase transitória de duas semanas pós-desmame (Cera et al., 1988). Deve-se ressaltar ainda que respostas de hipersensibilidade às proteínas da soja parecem ser causadas por proteínas antigênicas presentes na soja, como a glicina e a $\beta$ conglicina (Li et al. , 1991a), que são destruídas pelo tratamento térmico.

A relação peso de pâncreas/peso de carcaça foi semelhante entre os tratamentos $(\mathrm{P}>0,05)$, conforme apresentado na Tabela 6. Os valores encontrados neste trabalho estão de acordo com o relatado por Cera et al.(1990), que não observaram diferenças na relação entre o peso de pâncreas/peso corpóreo em animais alimentados com dietas à base de milho e soja, contendo ou não soro de leite. Entretanto, Efird et al. (1982) observaram que o crescimento do pâncreas em relação ao crescimento corpóreo foi maior em leitões que receberam dietas contendo proteína de soja que naqueles alimentados com dietas contendo leite.

Segundo Passile et al. (1989), a variação enzimática proveniente do pâncreas está associada ao ganho de peso. Dessa forma, animais mais pesados, poderiam responder de forma mais eficiente às mudanças dietéticas no desmame, por apresentarem sistema digestório mais desenvolvido. Como a fonte protéica parece ser um dos fatores mais importantes responsável pelas mudanças pancreáticas observa-

\begin{tabular}{|c|c|c|c|c|c|c|}
\hline \multirow[t]{2}{*}{$\begin{array}{l}\text { Parâmetro } \\
\text { Parameter }\end{array}$} & \multicolumn{5}{|c|}{$\begin{array}{l}\text { Níveis de substituição (\%) } \\
\text { Substituition levels (\%) }\end{array}$} & \multirow[t]{2}{*}{ CV (\%) } \\
\hline & 0 & 25 & 50 & 75 & 100 & \\
\hline $\begin{array}{l}\text { HVILOS }(\mathrm{mm})^{*} \\
\text { Villus height }(\mu \mathrm{m})\end{array}$ & 296,784 & 305,026 & 354,526 & 348,757 & 361,892 & 25,051 \\
\hline $\begin{array}{l}\text { PCRIP }(\mathrm{mm})^{*} \\
\text { Crypt depth }(\mu \mathrm{m})\end{array}$ & 139,575 & 125,883 & 145,077 & 158,359 & 143,793 & 35,533 \\
\hline $\begin{array}{l}\text { g pâncreas /kg carcaça* } \\
\text { g pancreas } / \mathrm{kg} \text { carcass }\end{array}$ & 3,456 & 3,497 & 2,680 & 3,308 & 3,258 & 18,278 \\
\hline
\end{tabular}

* n.s. não-significativo pelo teste $F$.

*n.s. not significant by $F$ test.

R. Bras. Zootec., v.33, n.6, p.2283-2291, 2004 (Supl. 3) 
das na fase de desmame (Rantzer et al., 1997), assim como pelo desenvolvimento pancreático, sendo mais dependente da mudança dietética que da idade neste período (Lindemann et al.,1986; Pierzynowky et al., 1993) - e, neste experimento, foram observadas diferenças entre os ganhos de peso, e não nas relações peso de pâncreas/peso corpóreo nos diversos tratamentos, pode-se afirmar que a proteína láctea e a proteína da soja processada estimularam o desenvolvimento pancreático em leitões de forma semelhante.

\section{Conclusões}

A utilização de isolado protéico de soja em rações para leitões dos 21 aos 35 dias de idade é viável, desde que não ocorra a substituição total da proteína láctea pela proteína da soja.

A proteína do isolado protéico de soja pode substituir a do leite em pó desnatado, para máximo ganho de peso, no nível de 34,25\% e de 51,00\%, para melhor conversão alimentar.

A substituição total da proteína láctea pela proteína da soja não afetou a integridade do vilo e a relação entre peso de pâncreas/peso de carcaça.

\section{Literatura Citada}

CERA, K.R.; MAHAN, D.C.; CROSS, R.F. et al. Effect of age, weaning and postweaning diet on small intestinal growth and jejunal morphology in young swine. Journal of Animal Science, v.66, p.574-584, 1988.

CERA, K.R.; MAHAN, D.C.; REINHART, G.A. Effect of weaning, week postweaning and diet composition on pancreatic and small intestinal luminal lipase response in young swine. Journal of Animal Science, v.68, p.384-391, 1990.

CHEN, S.C.; SHEN, T.F.; CHEN, S.Y. Effects of protein sources on the development of digestive enzymes in weaning pigs. Taiwan Sugar, v.39, p.48-23, 1992.

DECUYPERE, J.A.; MEEUSEN,A.; HENDERICKX, H.K. Influence of the partial replacement of milk protein by soybean protein isolates with different physical properties on the performance and nitrogen digestibility of early-weaned pigs. Journal of Animal Science, v.53, p.1011-1018, 1981.

DUNSFORD, B.R.; KNABE,D.A.; HAENSLY. W.E. Effect of dietary soybean meal on the microscopic anatomy of the small intestine in the early-weaned pig. Journal of Animal Science, v.67, p.1855-1863, 1989.

EASTER, R.A.; ODLE, J.; HOLLIS, G.R. et al. Dietary nutrient allowances for swine. Feedstuffs, p40-46, 1994.

EFIRD, R.C.; ARMSTRONG, W.D; HERMAN, D.L.The development of digestive capacity in young pigs: effects of weaning regimen and dietary treatment. Journal of Animal Science, v.55, p.370-1379, 1982.
ETHERIDGE, R.D.; SEERLEY, R.W.; WYATT, R.D. The effect of diet on performance, digestibility, blood composition and intestinal microflora of weaned pigs. Journal of Animal Science, v.58, p.1396-1402, 1984.

GRANT, A.L.; THOMAS, J.W.; KING, K.J. Effect of dietary amines on small intestinal variables in neonatal pigs fed soy protein isolate. Journal of Animal Science, v.68, p.363-371, 1990.

LI, D.F.; NELSSEN, J.L.; REDDY, P.G. et al. Transient hypersensitivity to soybean meal in the early-weaned pig. Journal of Animal Science, v.68, p.1790-1799, 1990.

LI, D.F.; NELSSEN, J.L.; REDDY, P.G. et al. Measuring suitability of soybean products for early-weaned pigs with immunological criteria. Journal of Animal Science, v.69, p.3299-3307, 1991a.

LI, D.F.; NELSSEN, J.L.; REDDY, P.G. et al. Interrelationship between hypersensitivity to soybean proteins and growth performance in early-weaned pigs. Journal of Animal Science, v.69, p.4062-4069, 1991b.

LINDEMANN, M.D.; CORNELIUS, S.G.; KANDELGY, S.M. et al. Effect of age, weaning and diet on digestive enzymes levels in the piglets. Journal of Animal Science, v.62, p.1298-1307, 1986.

MATEO, J.P.; VEUM, L. Utilization of casein or isolated soybean protein supplemented with amino acids and glucose or lactose by neonatal piglets reared artificially. Journal of Animal Science, v.50, p.869-876, 1980.

NABUURS, M.J.A. Microbiological, structural and functional changes of the small intestine of pigs at weaning. Pig News and Information, v.16, p.93N-97N, 1995.

NEWBY, T.J. Local hypersensitivity response to dietary antigens in early weaned pigs. In: COLE, D.J.A. (Ed.) Recent development in pig nutrition. London: Butterworths, 1985. p.211-29.

NEWPORT, M.J. Artificial rearing of pigs. 11. Effect of replacement of dried skim-milk and isolated soya-bean protein on the performance of the pigs and digestion of protein. British Journal of Nutrition, v.44, p.171-178, 1980.

NEWPORT, M.J.; KEAL, H.D. Artificial rearing of pigs. 12. Effect of replacement of dried skim-milk by either a soyaprotein isolate or concentrate on the performance of pigs and digestion of protein. Journal of Nutrition, v.48, p.89-96, 1982.

OWSLEY, W.F.; ORR JR., D.E.; TRIBBLE, L.F. Effects of age and diets on the development of the pancreas and the synthesis and secretion of pancreatic enzymes in the young pig. Journal of Animal Science, v.63, p.497-504, 1986.

PASSILLE, A.M.B.; PELLETIER, G.; MENARD, J. et al. Relationships of weight gain and behavior to digestive organ weight and enzyme activities in piglets. Journal of Animal Science, v.67, p.2921-2929, 1989.

PIERZYNOWSKI, S.G.; WESTROM, B.R.; ERLANSONALBERTSSON, C. et al. Induction of exocrine pancreas maturation at weaning in young developing pigs. Journal of Pediatric Gastroenterology and Nutrition, v.16, p.287-293, 1993.

POND, W.G.; SNYDER, W.; WALKER JR., E.F. et al. Comparative utilization of casein, fish protein concentrate and isolated soybean protein in liquid diets for growth of baby pigs, Journal of Animal Science, v.33, p.587-591, 1971.

RANTZER, D.; KIELA, P.; THAELA, M.J. et al. Pancreatic exocrine secretion during the first days after weaning in pigs. Journal of Animal Science, v.75, p.1324-1331, 1997. 
RATCLIFFE, B.; SMITH, M.W.; MILLER, B.G. et al. Effect of soya-bean protein on the ability of gnotobiotic pig intestine to digest and absorb nutrients. Journal of Agriculture Science, v.112, p.123-130, 1989.

ROBLES, A . Alimentacion del lechon. In: X MINI-SIMPÓSIO DO COLÉGIO BRASILEIRO DE NUTRIÇÃO ANIMAL NUTRIÇÃO E ALIMENTAÇÃO DE SUÍNOS. MINISIMPÓSIO DO COLÉGIO BRASILEIRO DE NUTRIÇÃO ANIMAL - NUTRIÇÃO E ALIMENTAÇÃO DE SUÍNOS, 10., 1993, Campinas. Anais... Campinas: Colégio Brasileiro de Nutrição Animal, 1993. p.83-89.

ROSTAGNO, H.S.; ALBINO, L.F.T.; DONZELE, J.L. et. al. Tabelas brasileiras para aves e suínos. Composição de alimentos e exigências nutricionais. 1.ed. Viçosa, MG: Universidade Federal de Viçosa, 2000. 141p.

STATISTICAL ANALYSES SYSTEM - SAS. Language guide for personal computer, 6.03, Cary: 1988.

SHERRY, M.P.; SCHMIDT, M.K.; VEUM, T.L. Performance of neonatal piglets mechanically fed diets containing corn, soybean meal and milk protein. Journal of Animal Science, v.46, p.1250-1258, 1978.

SOHN, K.S.; MAXWELL, C.V.; BUCHANAN, D.S. et al. Improved soybean protein sources for early -weaned pigs: I. Effects on performance and total tract amino acid digestibility. Journal of Animal Science, v.72, p.622-630, 1994a.
SOHN, K.S.; MAXWELL, C.V.; SOUTHERN, L.L. et al. Improved soybean protein sources for early-weaned pigs: II. Effects on ileal amino acids digestibility. Journal of Animal Science, v.72, p.631-637, 1994b.

STOKES, C.R.; MILLER, B.G.; BARLEY, M. et al. The immune response to dietary antigens and its influence on disease susceptibility in farm animals. Veterinary Immunology and Immunopathology, v.17, p.413-423, 1987.

WALKER, W.R.; MAXWELL, C.V.; OWENS, F.N. et al. Milk versus soybean protein sources for pigs: 1. Effects on performance and digestibility. Journal of Animal Science, v.63, p. 505-512, 1986.

WILSON, R.H.; LEIBHOLZ, J. Digestion in the pig between 7 and $35 \mathrm{~d}$ of age. 1.The performance of pigs given milk and soya-bean proteins. Journal of Nutrition, v.45, p.301-318, 1981a.

WILSON, R.H.; LEIBHOLZ, J. Digestion in the pig between 7 and $35 \mathrm{~d}$ of age. 3 . The digestion of nitrogen in pigs given milk and soybean proteins. Journal of Nutrition, v.45, p.337-346, 1981b.

Recebido em: 16/02/03

Aceito em: 26/08/04 